\title{
САНИТАРНОЕ ПРОСВЕЩЕНИЕ ДЛЯ ПРОФИЛАКТИКИ ЗАБОЛЕВАНИЙ: ОБЗОР ЛИТЕРАТУРЫ
}

\section{ОБЗОРНАЯ СТАТЬЯ}

GITIRANA, José Valdeci Almeida1, FONSECA, Rosa Maria Batista Pinheiro da², PILONETO, Fábio Marmentini ${ }^{3}$, BEVILAQUA, Luis Felipe Gaia ${ }^{4}$, ASSIS, Ingrid de ${ }^{5}$, CARDOSO, Ronald de Oliveira ${ }^{6}$

GITIRANA, José Valdeci Almeida. Et al. Санитарное просвещение для профилактики заболеваний: обзор литературы. Revista Científica Multidisciplinar Núcleo do Conhecimento. Год. 06, Изготовить. 11, Vol. 08, с. 134147. Ноябрь 2021 года. ISSN: 2448-0959, Ссылка доступа: https://www.nucleodoconhecimento.com.br/здравоохранение/санитарноепросвещение, DOI: 10.32749/nucleodoconhecimento.com.br/ru/102791

\section{СВОДКА}

В настоящее время государственная политика, действия правительства и различные программы, связанные с Санитарное Просвещение (ES), осуществляются в пользу здоровья населения. Что касается темы ES, то это многогранная тема, сходящаяся с различными личными концепциями, будь то в области образования или здравоохранения, что может привести к различным пониманиям. Из-за сложности темы проблема возникает из-за непонимания того, что на самом деле является населением ES, что растворяет важность ES для профилактических мер против различных заболеваний, что порождает

\footnotetext{
${ }^{1}$ Окончила фармацевтический факультет, аспирантура по клиническому анализу, в настоящее время медицинский академик.

2 Медицинский ученый.

${ }^{3}$ Окончила администрацию. Закончил факультет внешней торговли, в настоящее время студент-медик.

${ }^{4}$ Окончил факультет пищевой инженерии, аспирантуру по специальности «Инженерия промышленных процессов», СВА по управлению бизнесом, а в настоящее время студент-медик.

${ }^{5}$ Медицинский ученый.

${ }^{6}$ Медицинский ученый.
}

RC: 102791

Доступно в:

https://www.nucleodoconhecimento.com.br/здравоохранение/санитарное- 
высокие бюджетные расходы в общественном здравоохранении. В связи с этим контекстом в данной статье основным вопросом является: каким образом санитарное просвещение может способствовать профилактике заболеваний среди населения? Исследование было направлено на то, чтобы представить ES для профилактики заболеваний (PD), разветвляясь в рассмотрении его концепций, а также подчеркивая правовые основы, которые обеспечивают ES для населения. С этой целью исследование проводилось через обзор литературы поисковым сайтом «Google Scholar», «Scielo» и «PubMed». Через дескрипторы: санитарное просвещение; Санитарное просвещение как профилактика заболеваний; Санитарное просвещение населения, где были выбраны исследования, которые представляли ES, ориентированные на PD. Делается вывод, что ES - это воспитание для самопознания и размышлений о собственном здоровье, а также полного осознания того, что что-то идет не так, приписывая критическое осмысление субъекта относительно своих привычек и профилактических мер. Он применяется через школьную программу с начальной школы, а также в рамках государственных программ в медицинских центрах, чтобы просвещать общество для повышения осведомленности о профилактических мерах и содействия улучшению качества жизни, тем самым предотвращая распространение заболеваний.

Ключевые слова: Санитарное Просвещение, профилактика заболеваний, укрепление здоровья, население.

\section{1. ВСТУПЛЕНИЕ}

Санитарное просвещение (ES) - это социальная практика, процесс обучения которой способствует формированию критического личного осознания самих проблем со здоровьем, заставляя гражданина задуматься об их реальности, а из нее искать решения и организацию в пользу своего здоровья и коллективного здоровья, результатом является Укрепление здоровья (PS) (BISCARDE; PEREIRA-SANTOS; SILVA, 2014).

RC: 102791

Доступно в:

https://www.nucleodoconhecimento.com.br/здравоохранение/санитарное- 
Происхождение и концепции PS начались с появлением ES в начале 20-го века, через наблюдение за снижением заболеваемости в результате образовательной практики, выполняемой «гигиенистами» [7] того периода (ENRIA; STAFOLANI, 2010). В то время значение PS приписывалось действиям ES, с целью улучшения качества жизни. Однако ES в настоящее время имеет усиленную характеристику, так как считается одним из основных устройств для жизнеспособности PS, что приводит к развитию индивидуальной ответственности и Профилактики заболеваний (PD) (LOPES; SARAIVA; XIMENES, 2010; FALKENBERG et al., 2014; SPERANDIO; SPERANDIO, 2018).

Хотя ES понимается как одна из мер для PD (JANINI; BESSLER; VARGAS, 2015; SPERANDIO; SPERANDIO, 2018), это многогранная тема, сходящаяся к различным личным концепциям, будь то для людей в области образования или в области здравоохранения, что может привести к различным пониманиям. (SCHALL; STRUCHINER, 1999).

Из-за сложности темы проблема возникает из-за непонимания того, что на самом деле является населением ES, растворяя важность ES для профилактических мер против различных заболеваний. Из-за этого часто доказывают, что многие заболевания, которых можно было бы избежать, оказывают серьезное влияние на государственный бюджет. Поэтому настоящее исследование было ответом на вопрос: каким образом санитарное просвещение может способствовать профилактике заболеваний среди населения? Посредством обзора литературы общая цель состояла в том, чтобы представить, как ES может продвигать PD, разветвляясь в решении своих концепций, а также подчеркивая правовые основы, которые обеспечивают ES для населения.

С этой целью исследование проводилось через обзор литературы поисковым сайтом «Google Scholar», «Scielo» и «PubMed». Через дескрипторы: санитарное просвещение; Санитарное просвещение как профрилактика заболеваний;

RC: 102791

Доступно в:

https://www.nucleodoconhecimento.com.br/здравоохранение/санитарное- 
Санитарное просвещение населения. В качестве способа включения были выбраны статьи и документы в период с 2018 по 2020 год, составляющие необходимую структуру для достижения желаемой цели. Впоследствии было найдено 20 статей, из которых 8 были отобраны. Были включены статьи, отвечающие на вопрос о цели и руководстве и находящийся в предложенных сроках. Исследования, направленные только на медицинских работников или студентов, квалифицированных в области здравоохранения, были исключены.

Тема актуальна и сегодня, так как ES может влиять на способность населения размышлять о борьбе с различными заболеваниями, что приводит к улучшению жизненных привычек. Он может быть актуален для непрофессионалов или для студентов и профрессионалов в академической области, выступая в качестве источника для будущих исследований, потому что он просвещает концепцию ES для населения как неотделимого от PD, предоставляя язык, который легко понять.

\section{2. САНИТАРНОГО ПРОСВЕЩЕНИЯ И ПРОФИЛАКТИКИ ЗАБОЛЕВАНИЙ}

ES планируется и применяется по-разному, такая модальность обучения может быть направлена на магистрантов в области здравоохранения; для медицинских работников; для школьного образования и населения в целом. На самом деле, она имеет тенденцию пониматься по-разному, встречая культурную и социальную фрормацию каждого из них. Однако в настоящем исследовании подчеркивается ES для населения неотделимо от PD , поскольку ES если «[...] связано с общими целями общественного здравоохранения: профилактика заболеваний, защита и укрепление здоровья человека, семьи и общества». (PIMONT, 1997, р. 17).

Чтобы лучше контекстуализировать понимание этой неразделимости, важно подчеркнуть, что ES является одним из них:

$\mathrm{RC}: 102791$

Доступно в:

https://www.nucleodoconhecimento.com.br/здравоохранение/санитарное- 
Processo educativo de construção de conhecimentos em saúde que visa à apropriação temática pela população [...]. Conjunto de práticas do setor que contribui para aumentar a autonomia das pessoas no seu cuidado e no debate com os profissionais [...] a fim de alcançar uma atenção de saúde de acordo com suas necessidades. (BRASIL, 2012, p. 19).

Как представлено в «Тематическом глоссарии: управление работой и санитарное просвещение », ES обусовывает желаемую автономию, чтобы люди могли эффрективно выражать себя, чтобы доказать свои конкретные потребности в своей клинической помощи, способствуя заботе медицинского работника для быстрого лечения заболеваний, а также профилактики других вторичных заболеваний. В дополнение к этому определению в документе Национального фронда здравоохранения (FUNASA) Бразилия (2007 год) представлено, что ES является социальной практикой, подтверждая, что ее намерение вплетается в трансформацию для любого типа человека, « [...] нарушая парадигму статической концепции образования как передачи знаний, навыков и навыков». (BRASIL, 2007, р. 20).

Pimont (1997, р. 15) резюмирует и анализирует различные принятые концепции, подчеркивая, что ES стремится обеспечить:

1) A consciência do direito à saúde, dentro do grau de desenvolvimento do grupo social no qual vive o indivíduo; 2) 0 conhecimento sobre saúde; 3) O conhecimento dos serviços para a saúde que a comunidade possua e sua consequente utilização; 4) 0 conhecimento e a utilização das práticas de saúde.

Тем не менее, автор понимает, что для преобразования этого обучения в знания с целью продвижения PS и PD необходимо, чтобы планирование было структурировано, смягчая адекватную образовательную методологию, состоящую из вспомогательных инструментов, которые затем могут привести к постоянному процессу обучения. .

Согласно Алтуве (1996), для того, чтобы ES стала знанием, организация сообщества уже становится методом, который производит социальные

RC: 102791

Доступно в:

https://www.nucleodoconhecimento.com.br/здравоохранение/санитарное- 
изменения, потому что в разгар усилий и методов его применение приводит к индукции и продвижению значительных социальных изменений, охватывающих все социальные сектора, такие как отношения экономического, политического и образовательного уровней.

Поэтому, по мнению цитируемых авторов, ES может быть неотделимы от PD к населению, при передаче методологически. Однако настоящее исследование направлено не на углубление этих методологий, а на концептуализацию ES как PD для населения.

\section{1 ПРАВОВАЯ ОСНОВА ЗДРАВООХРАНЕНИЯ НАСЕЛЕНИЯ}

С уделением особого внимания ES в Бразилия в августе 1971 года был принят Закон № 5692, в соответствии с которого была пересмотрена школьная программа в области начального и среднего образования, в рамках которого осуществляется ориентированное на здоровье образование, представленное в статье 7:

Art. 7ํㅗㄴ Será obrigatória a inclusão de Educação Moral e Cívica, Educação Física, Educação Artística e Programas de Saúde nos currículos plenos dos estabelecimentos de ํo e $2^{0}$ graus, observado quanto à primeira o disposto no Decreto-Lei n. 369, de 12 de setembro de 1969. (Vide Decreto no 69.450, de 1971)

Более поздние программы como «Saúde na escola», использовались в качестве межсекторальной стратегии, разработанной в школьном пространстве и его окрестностях, фрормулируя действия, направленные на PS и качество жизни, вместе с размышлениями о PD и знанием Единая система здравоохранения (SUS) (BRASIL, 2012.) Этот контекст может быть подчеркнут тем фрактом, что действия для ES реализовываться на протяжении всей жизни, начиная с первого этапа школьного образования, чтобы у людей постепенно развивалось критическое, рефлексивное и сознательное чутье.

RC: 102791

Доступно в:

https://www.nucleodoconhecimento.com.br/здравоохранение/санитарное- 
Положительно прерывая охват программ, направленных на ES и PD, были созданы различные законы в соответствии с правовыми основаниями, представленными в таблице 1 ниже:

\section{Таблица 1 - Правовые основы Санитарное Просвещение.}

A Lei n. ${ }^{\circ}$ 8.080/1990, que regulamenta o SUS, em seu Capítulo I, Art. $5^{\circ}$, Item III, define como um dos objetivos e atribuições deste Sistema: "a assistência às pessoas por intermédio de ações de promoção, proteção e recuperação da saúde, com a realização integrada das ações assistenciais e das atividades preventivas". A mesma Lei, em seu Capítulo II, Artigo 7_, Item VIII, estabelece a "participação da comunidade."

A Lei $\mathbf{N}^{\circ}$ 8.142, de 28 de dezembro de 1990, define a participação da comunidade na gestão SUS e no seu artigo $1^{\circ}$ "as instâncias colegiadas de controle social: I) a Conferência de Saúde, e II) o Conselho de Saúde."

A Norma Operacional Básica - SUS 1/1996 (NOB/96), que redefine as responsabilidades dos estados, do Distrito Federal e da União e consolida as responsabilidades dos municípios, cita como um dos papéis do gestor federal e do estadual a "Educação em Saúde

A Educação em Saúde na Funasa está ancorada em seu Regimento Interno, Portaria GM n ${ }^{\circ} 1.776$ de 8/9/2003, assinada pelo Ministro da Saúde que estabelece as competências da Assessoria de Comunicação e Educação em Saúde-Ascom e seus setores, dentro das competências dos demais setores do órgão. (...)

Lei n. 9.394, de 20 de dezembro de 1996 (1996). Estabelece as diretrizes e bases da educação nacional.

DCN - EF 1988 - Estabelecer as Diretrizes Curriculares Nacionais para o Ensino Fundamental: Saúde articulada à educacão e à vida cidadã.

PCN - CN 1988 - Estabelecer as Referências Nacionais Comuns para o Ensino das Ciências Naturais: Saúde como estado de equilíbrio dinâmico do corpo.

PCN - TT Saúde 1988 - Apresentar a saúde como um Tema Transversal: Educação para a saúde PCN - EM 1999 - Apresentar os Parâmetros Curriculares Nacionais para o Ensino Médio: Degradação ambiental e agravos à saúde humana.

PCN + 2002 - Apresentar Orientações Curriculares complementares aos PCN: Saúde e as condições de vida das pessoas.

OCEM 2006 - Apresentar sugestões para as práticas pedagógicas e organização dos currículos do Ensino Médio: Ambiente e saúde.

DCNEB 2013 - Estabelecer Orientações Nacionais para a Educação Básica. Saúde como campo de conhecimento e de serviços.

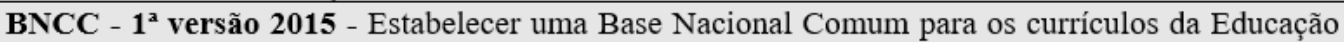
Básica, com versão inicial disponibilizada para consulta pública, estabelecendo cuidado com a saúde da população.

BNCC - $2^{\mathbf{a}}$ versão 2016 - Estabelecer uma Base Nacional Comum para os currículos da Educação Básica, com versão elaborada após contribuições da sociedade, para o ambiente e saúde.

BNCC $3^{\text {a }}$ versão 2016 - Estabelecer uma Base Nacional Comum para os currículos da Educação Básica com versão disponibilizada após contribuições institucionais, para promoção dos cuidados com a saúde.

BNCC versão final (EI e EF) 2016 - Estabelecer uma Base Nacional Comum para os currículos da Educação Infantil e do Ensino Fundamental, compondo a versão final, com o objetivo de promover os cuidados com a saúde.

BNCC EM 2018 - Estabelecer uma Base Nacional Comum para os currículos do Ensino Médio, promoção do cuidado com a saúde.

Источник: Адаптировано из Brasil (2012); Sousa, Guimarães u Amantes (2019).

RC: 102791

Доступно в:

https://www.nucleodoconhecimento.com.br/здравоохранение/санитарное- 
В рамочной программе представлены законы, В которых подчеркиваются некоторые образовательные основы для применения ES в школе, даже если такие руководящие принципы сосредоточены на школьной среде, учебные цели направляют формирование людей, которые понимают важность ES и которые с помощью этих знаний могут способствовать заботе о личном и демографических здоровье, также составляющий благотворителя PD.

Сегодня Организация Объединенных Наций представляет третью цель в «Повестке дня на период до 2030 года», и при глобальной поддержке она предназначена через действие «Обеспечить здоровую жизнь и содействовать благополучию для всех и всех, во всех возрастах» (ODS, 2021) независимо от социального класса, расы или цвета кожи.

Место в повестке дня на период до 2030 года соответствует точке зрения SHALL (1999), когда она смягчает, что определение ES должно быть более широким, чем просто действие, вытекающее из PS, поскольку оно ориентировано на население, проходит через всеобъемлющий процесс активного участия всего населения в контексте их повседневной жизни, а не только людей, которые рискуют заболеть, будучи тогда способом профрилактики заболеваний для здоровых людей, установления лучшего качества жизни и большего благополучия для всех.

\section{2 ИССЛЕДОВАНИЯ, СВЯЗАННЫЕ С ПРОФИЛАКТИКОЙ ЗАБОЛЕВАНИЙ ПОСРЕДСТВОМ САНИТАРНОГО ПРОСВЕЩЕНИЯ}

Затем будут представлены основные выводы о PD в результате применения ES, доступные в научной литературе, в период с 2018 по 2020 годы. В таблице 2 ниже суммируются 8 ранее выбранных статей, представленных в хронологическом порядке, где методологии использованные в каждом исследовании будут объяснены позже.

RC: 102791

Доступно в:

https://www.nucleodoconhecimento.com.br/здравоохранение/санитарное- 
Таблица 2 - Исследования, связанные с санитарно-просветительской работой как профилактикой заболеваний.

\begin{tabular}{|c|c|c|}
\hline Автор & Цель & Заключение \\
\hline $\begin{array}{l}\text { Dias et al. } \\
(2018)\end{array}$ & $\begin{array}{l}\text { Сообщить об опыте } \\
\text { мероприятия по санитарному } \\
\text { просвещению с учащимися } \\
\text { начальных школ из } \\
\text { государственной школы в } \\
\text { сельских районах. }\end{array}$ & $\begin{array}{l}\text { Дети подвергаются риску } \\
\text { заражения паразитами, учитывая } \\
\text { санитарные условия, в которых } \\
\text { они обитают, что свидетельствует } \\
\text { о необходимости расширения } \\
\text { мероприятий по санитарному } \\
\text { просвещению о важности } \\
\text { профилактики паразитов. }\end{array}$ \\
\hline $\begin{array}{l}\text { Salci, } \\
\text { Meirelles e } \\
\text { Silva (2018) }\end{array}$ & 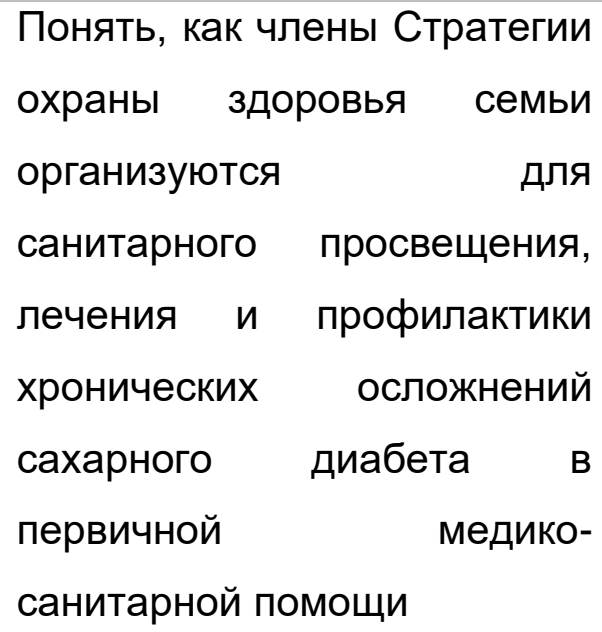 & $\begin{array}{l}\text { Считается, что практика } \\
\text { санитарного просвещения людей } \\
\text { с сахарным диабетом в системе } \\
\text { первичной медико-санитарной } \\
\text { помощи является частью } \\
\text { многогранного контекста с } \\
\text { множеством препятствий для его } \\
\text { реализации. }\end{array}$ \\
\hline $\begin{array}{l}\text { Gomes et } \\
\text { al. (2019) }\end{array}$ & $\begin{array}{lr}\text { Сообщить } & \text { об } \\
\text { образовательных действиях } \\
\text { в группе мужчин, чтобы } \\
\text { лучше понять рак полового } \\
\text { членом и } \\
\text { профилактики и раннего } \\
\text { выявления. }\end{array}$ & $\begin{array}{l}\text { Знания о раке полового железа } \\
\text { все еще нуждаются в лучшей } \\
\text { проработке среди мужчин. }\end{array}$ \\
\hline Figueiredo; & $\begin{array}{llr}\text { Привести } & \text { к } & \text { созданию } \\
\text { политики } & \text { в } & \text { области }\end{array}$ & $\begin{array}{l}\text { Государственная политика имеет } \\
\text { важнейшее } \quad \text { значение }\end{array}$ \\
\hline
\end{tabular}

RC: 102791

Доступно в:

https://www.nucleodoconhecimento.com.br/здравоохранение/санитарное- 


\begin{tabular}{|c|c|c|}
\hline & $\begin{array}{l}\text { просвещения в области } \\
\text { общественного } \\
\text { здравоохранения с особым } \\
\text { уходом за школами и } \\
\text { должным направлением } \\
\text { учащихся с ожирением в } \\
\text { медицинские отделения }\end{array}$ & 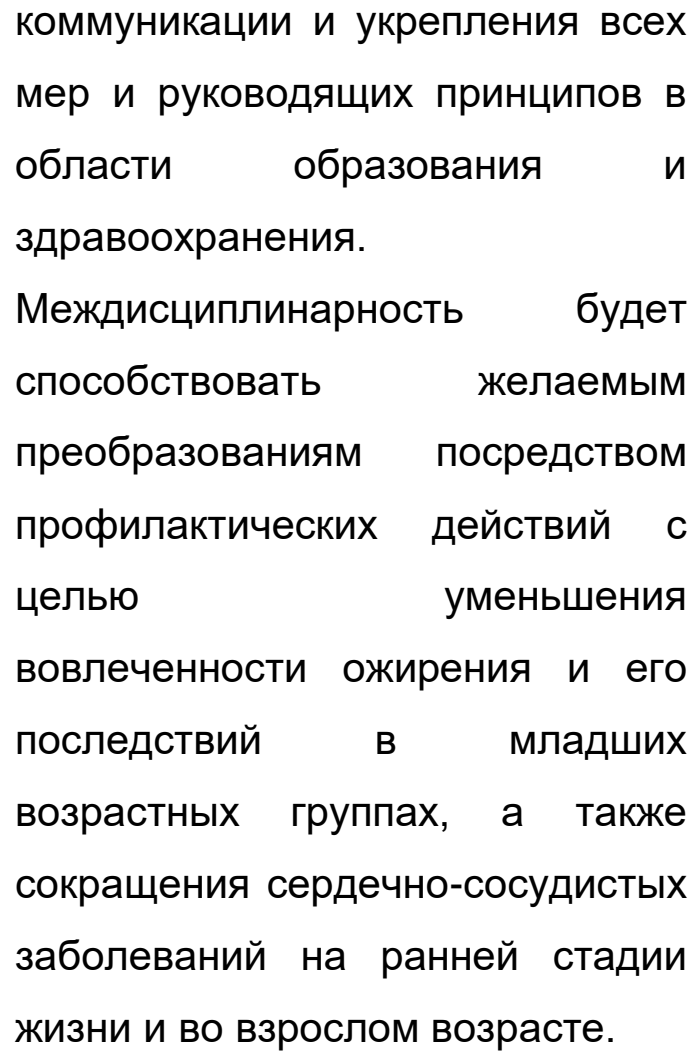 \\
\hline $\begin{array}{l}\text { Ricci et al. } \\
(2019)\end{array}$ & $\begin{array}{l}\text { Сообщите об опыте ученых } \\
\text { из Федерального } \\
\text { университета Мату-Гросу-ду- } \\
\text { Сул (UFMS) во время акции, } \\
\text { разработанной с группой } \\
\text { беременных женщин из } \\
\text { отделения базового } \\
\text { здравоохранения в Кампу- } \\
\text { Гранди - MS (UBS). }\end{array}$ & 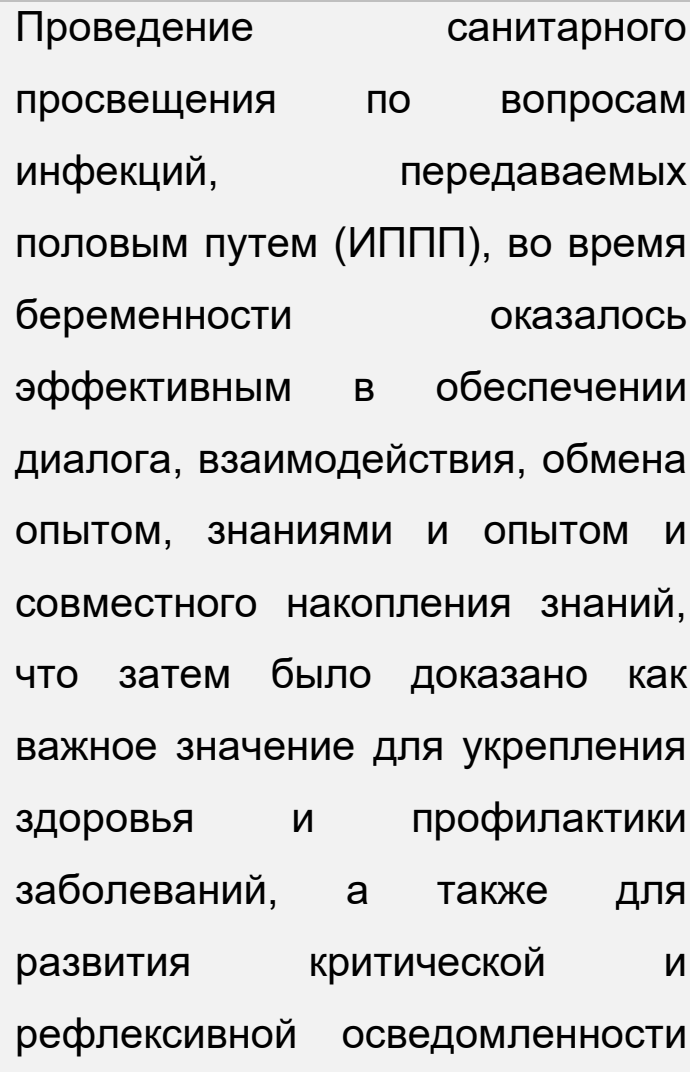 \\
\hline
\end{tabular}

RC: 102791

Доступно в:

https://www.nucleodoconhecimento.com.br/здравоохранение/санитарное- 


\begin{tabular}{|c|c|c|}
\hline & & $\begin{array}{l}\text { беременных женщин об их } \\
\text { процессе болезни со здоровьем, } \\
\text { делая их активными в процессе } \\
\text { обучения. }\end{array}$ \\
\hline $\begin{array}{l}\text { De Sousa } \\
\text { Gonçalves } \\
\text { et al. (2020) }\end{array}$ & $\begin{array}{l}\text { Знать работу санитарного } \\
\text { просвещения } \\
\text { медицинского } \\
\text { подразделения } \\
\text { муниципалитете Императрис } \\
\text { - МА. }\end{array}$ & 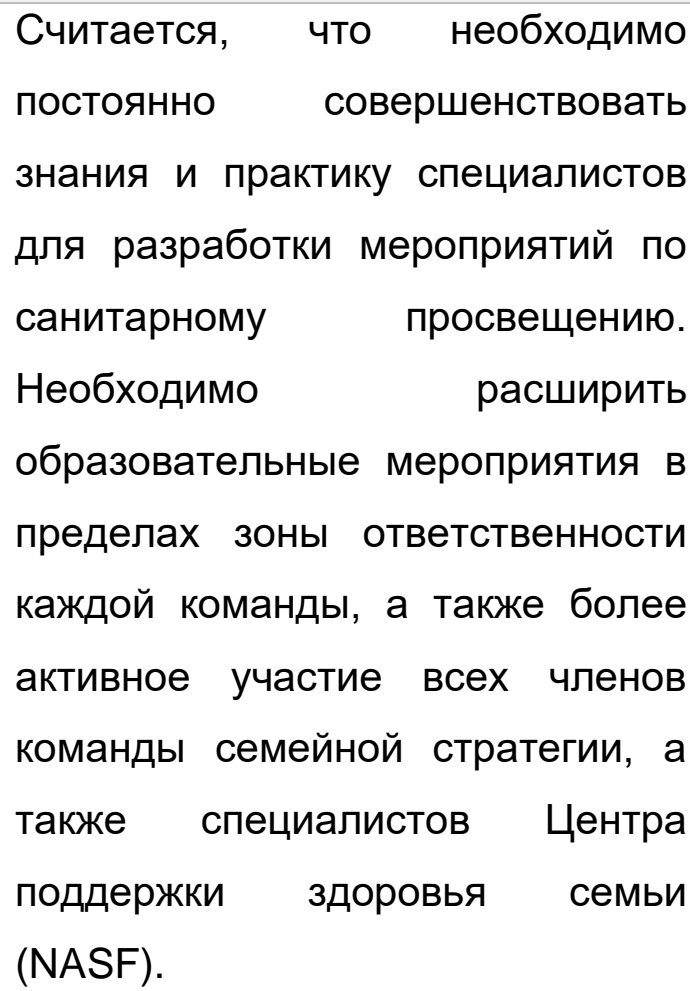 \\
\hline $\begin{array}{l}\text { Lima et al. } \\
(2020)\end{array}$ & $\begin{array}{l}\text { Опишите опыт студентов } \\
\text { сестринского дела } \\
\text { мероприятиях } \\
\text { санитарному просвещению } \\
\text { для профилактики сердечно- } \\
\text { сосудистых заболеваний у } \\
\text { пожилых людей. }\end{array}$ & 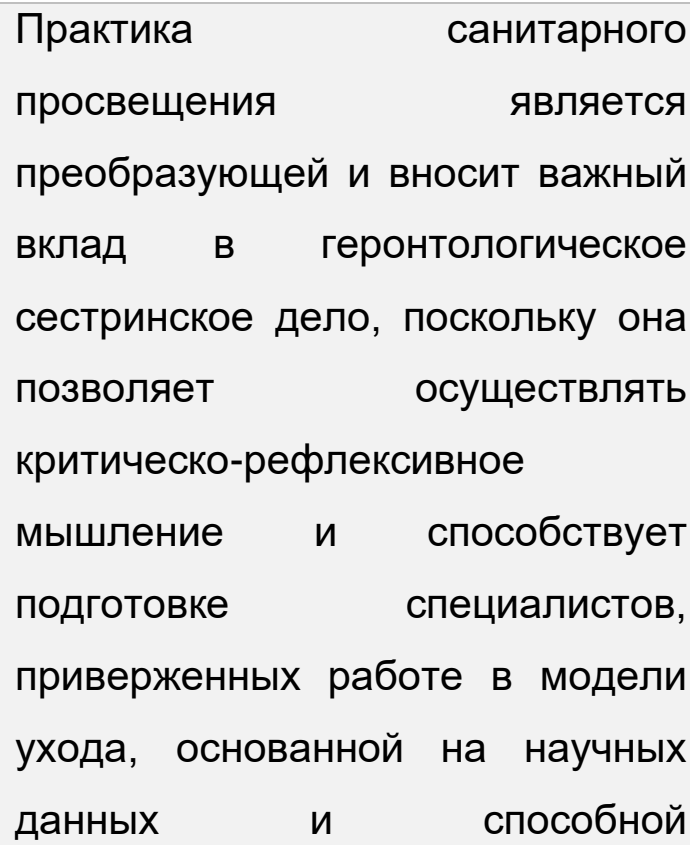 \\
\hline
\end{tabular}

RC: 102791

Доступно в:

https://www.nucleodoconhecimento.com.br/здравоохранение/санитарное- 


\begin{tabular}{|c|c|c|}
\hline & & $\begin{array}{l}\text { удовлетворить потребности } \\
\text { пожилого населения, которая } \\
\text { растет на протяжении многих лет. }\end{array}$ \\
\hline $\begin{array}{l}\text { Costa et al. } \\
(2020)\end{array}$ & 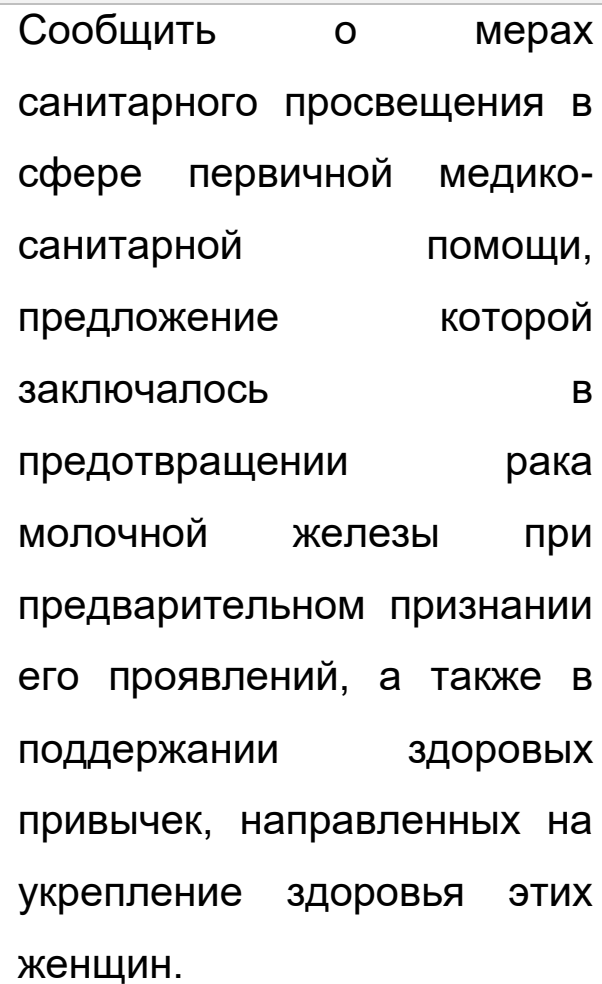 & 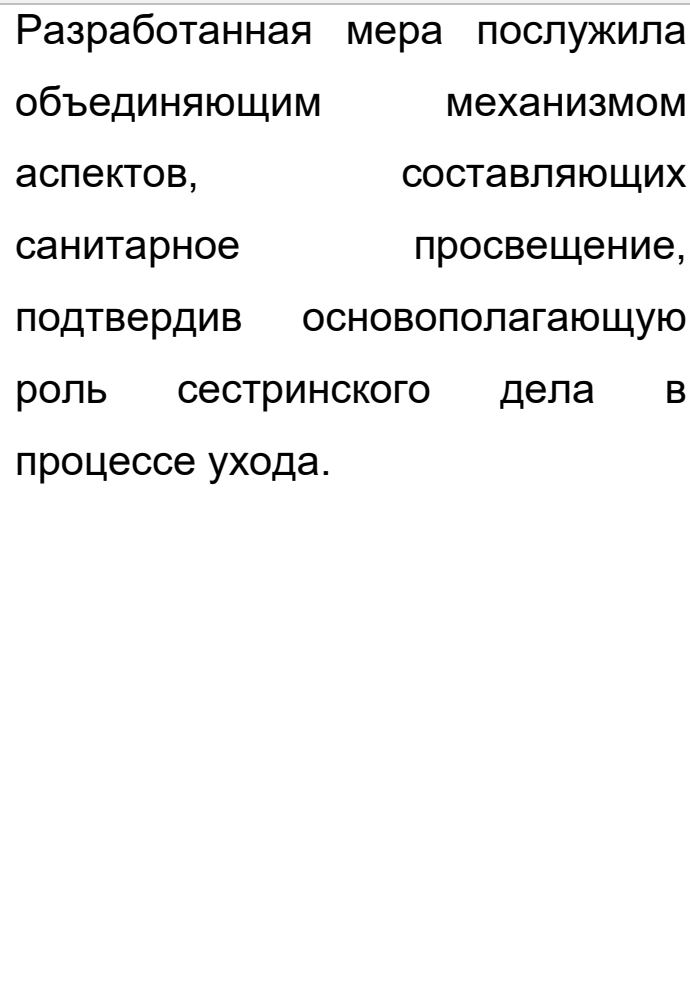 \\
\hline
\end{tabular}

Источник: Автор.

Dias et al. (2018), через отчет об опыте с внеклассным методом деятельности учебного компонента «Научно-интеграторный проект сестринского дела для студентов» фракультета Verde Norte, проведенный в октябре 2016 года в муниципальной школе Odilon Antunes, в деревне Роçо̃es города Монте-Азул, акция санитарного просвещения с участием 30 студентов, 03 учителя и 09 родителей. Действие происходило на этапах диалогической экспозиции контента и в отображении триггера видеообсуда, будучи обсуждаемым в колесе разговоров с аудиторией. Таким образом, исследование обеспечило профилактические меры при заражении паразитарными заболеваниями.

RC: 102791

Доступно в:

https://www.nucleodoconhecimento.com.br/здравоохранение/санитарное- 
Salci; Meirelles и Silva (2018) провел качественное исследование, составив комплексное мышление в качестве теоретического ориентира и оценочное исследование в качестве методологического справочника. Для сбора данных 38 медицинских работников опросили пациентов с сахарным диабетом. Медицинские агенты наблюдали и анализировали медицинские записи пациентов путем триангуляции данных при поддержке программного обеспечения ATLAS.ti. Авторы отметили, что в соответствии со сложностью многогранной темы, ES может продвигать первичные и вторичные PD.

Подтверждая эту сложность, Figueiredo; Antunes и De Miranda (2019) провели библиографическое обзорное исследование, применив метод поискового исследования. Авторы относили профрилактику сопутствующих заболеваний и сердечно-сосудистых заболеваний к государственной политике ES в школьной среде. Поэтому они подчеркнули, что междисциплинарность, которая включает в себя ES, может способствовать желаемым преобразованиям у студентов посредством профилактических действий, профилактики сердечно-сосудистых заболеваний в детстве и взрослой жизни.

Lima et al. (2020) в аналогичном исследовании, но ориентированном на пожилых людей, они отметили через отчет об опыте, описательным методом, с качественным подходом, испытанного в «Программе здравоохранения для пожилых людей - PROASI», что деятельность ES служит инструментом в профилактике сердечно-сосудистых заболеваний, вызывая критическирефлексивное мышление к собственному здоровью и качеству жизни.

Gomes et al. (2019) благодаря исследовательскому описательному исследованию типа отчета об опыте они применили деятельность, проведенную в марте 2018 года в церкви, расположенной на окраине Белен / Пара. Участвующая общественность состояла из двадцати трех мужчин в возрасте от 18 до 50 лет, которые были представлены на лекции с вручением баннеров; объяснение рака полового членского пояса; уход за PD и 
демонстрация протезов полового членом. Авторы наблюдали через колесо разговора с участниками, которые мало кто знал о теме рака полового членского рубля. Поэтому авторы предупреждают о важности реализации программ ES, ориентированных на PD, таких как рак полового члена, поскольку с программами, ориентированными на ES, это и другие заболевания могут быть значительно снижены в популяции.

Bce еще в контексте профрилактики рака, Costa et al. (2020), провел описательное исследование с качественным подходом, типа отчета об опыте. Исследование проводилось в больничном районе города Белен-Па, в медицинском подразделении с профессионалами, которые пропагандируют метод лечения, ориентированный на первичный уровень заболеваний. Лечение, предназначенное для женской общественности, консолидировано в рамках осуществления "Программы охраны здоровья женщин", в рамках которой пациенты лечатся с помощью дородового ухода; роды; послеродовой период; уход за семьями; программы профилактики рака молочной железы и матки; ИППП. Эта программа состоит из профессионалов из различных областей здравоохранения, вместе с различными типами клинических анализов для принятия профилактических мер, способствующих предыдущей диагностике патологий, таких как рак. С внедрением образовательного мероприятия в программу медицинские работники следили за пациентами в их консультациях, и аналогично исследованию Gomes et al. (2019) открытые папки; анатомические проявления молочной железы; среди других образовательных и интерактивных мероприятий. Таким образом, авторы разъяснили, что 16 участников больше размышляли о важности самообслуживания и понимали важность ES для профилактики рака молочной железы.

Не то чтобы это касается отражения, упомянутого Gomes et al. (2019) Ricci et al. (2019) подтверждают, что этот процесс осознания происходит посредством диалога; взаимодействие; обмен опытом; знания и опыт, а также совместное построение знаний, которые затем были выделены как важные для PS и PD.

RC: 102791

Доступно в:

https://www.nucleodoconhecimento.com.br/здравоохранение/санитарное- 
Это наблюдение было подтверждено в исследовании, которое проводилось 15 марта 2017 года во второй половине дня в конференц-зале отделения базовой медицинской помощи в Кампу-Гранди - штат Миссисипи. Стратегическим образом использовалась методология, состоящая из игровых практик с целью интерактивности участников, чтобы через педагогическую практику они могли получить понимание рассматриваемой темы. Первоначально, как беременные участницы, их приглашали по звонку соответствующие агенты в районе отделения здравоохранения. Впоследствии действие началось $\mathrm{c}$ ледокольной техники «Передача ребенка», в которой участники считались идентифицирующими себя по имени, сроку беременности и выбору имени ребенка. Благодаря динамике беременные женщины узнали о заболеваниях, которые можно предотвратить во время беременности, а также о PD у самого ребенка.

Для того, чтобы это рефлексивное осознание вовлекло семью, De Sousa Gonçalves et al. (2020), проведена количественная работа с аналитическим подходом, основанная на ретроспективном сборнике действий $E S$, осуществленных с февраля по сентябрь 2019 года. Исследование проводилось в Базовая единица здоровья (UBS) муниципалитета Императрис в штате Мараньян, в состав которой входят 3 группы по стратегии семейного здравоохранения. Были собраны данные из коллекции документов с записями о действиях ES, совершенных в UBS и в школах района, охваченных каждой группой в вышеупомянутый период, предоставленных руководством медицинского подразделения. Авторы проанализировали, что с помощью ES можно предотвратить не только хронические, сексуальные или инфекционные заболевания, но и профиилактические меры могут быть результатом программ, которые помогают этим семьям.

RC: 102791

Доступно в:

https://www.nucleodoconhecimento.com.br/здравоохранение/санитарное- 


\section{3. ОКОНЧАТЕЛЬНЫЕ СООБРАЖЕНИЯ}

ES может продвигать PD через программы государственной политики, направленные на реализацию образовательных программ ES в школах, UBS, больничных сетях, а также медицинских пунктах. Для этого его концепции могут быть широко представлены, так как ES является сложной и многогранной темой.

На основе выводов считается, что ES может стимулировать PD совместно с PS для населения, когда происходит вовлечение этой целевой аудитории посредством методологически спланированных мероприятий и применяемых с участием конкретных инструментов развития обучения. Что касается PD, B исследованиях обнаружено несколько профилактических профилактических препаратов: сердечно-сосудистые, диабет, хронические неинфекционные заболевания, инфекционные заболевания, передающиеся половым путем, паразитарные заболевания, рак и другие.

В контексте законов и правовых основ ES, он направлен на большие ожидания у учащихся ранних ступеней и средней школы, поскольку образовательный процесс не навязывается во взрослой жизни, а может быть построен в течение жизни, становясь знаниями.

Поэтому в ответ на правильно мыслящий вопрос делается вывод, что ES - это воспитание для самопознания и размышлений о собственном здоровье, а также полного осознания того, что что-то идет не так, приписывая критическое размышление субъекта относительно своих привычек и профилактических мер, тем самым предотвращая заболевания. Он применяется через школьную программу с начальной школы, а также в рамках государственных программ в медицинских центрах, чтобы просвещать общество для повышения осведомленности о профилактических мерах и содействия улучшению качества жизни.

RC: 102791

Доступно в:

https://www.nucleodoconhecimento.com.br/здравоохранение/санитарное- 


\section{ИСПОЛЬЗОВАННАЯ ЛИТЕРАТУРА}

ABREU JUNIOR, Laerthe de Moraes; CARVALHO, Eliane Vianey de. O discurso médico-higienista no Brasil do início do século XX. Trabalho, Educação e Saúde, v. 10, p. 427-451, 2012.

ALTUVE. R. L. O. La organización de la comunidad como un proceso educativo. Cuadernos de la Escuela de Salud Pública (Caracas) 4:9-28, 1966

BISCARDE, Daniela Gomes dos Santos; PEREIRA-SANTOS, Marcos; SILVA, Lília Bittencourt. Formação em saúde, extensão universitária e Sistema Único de Saúde (SUS): conexões necessárias entre conhecimento e intervenção centradas na realidade e repercussões no processo formativo. Interface-Comunicação, Saúde, Educação, v. 18, p. 177-186, 2014.

BRASIL. Fundação Nacional de Saúde. Diretrizes de educação em saúde visando à promoção da saúde: documento base - documento I/Fundação Nacional de Saúde -Brasília: Funasa, 2007.

. Ministério da Saúde (MS) Glossário temático: gestão do trabalho e da educação na saúde. Brasília DF, 2012. Disponível em: https://bvsms.saude.gov.br/bvs/publicacoes/glossario_gestao_trabalho_2ed.pdf Acesso em: 03/07/2021. . Lei; LEI, №. 5.692, DE 11 DE AGOSTO DE 1971. Fixa Diretrizes e Bases para o ensino de, v. 1, p. 6377, 1971.

. Lei n. 9.394, de 20 de dezembro de 1996 (1996). Estabelece as diretrizes e bases da educação nacional. Brasília, DF: Ministério da Educação. Disponível em: http://portal.mec.gov.br/seed/arquivos/pdf/tvescola/leis/ lein9394.pdf Acesso em 20 de ago. 2021.

RC: 102791

Доступно в:

https://www.nucleodoconhecimento.com.br/здравоохранение/санитарное- 
COSTA, Paula Valéria Dias Pena et al. A educação em saúde como ferramenta no combate ao câncer de mama: relato de experiência. Research, Society and Development, v. 9, n. 10, p. e6389108912-e6389108912, 2020.

DE SOUSA GONÇALVES, Romário et al. Educação em saúde como estratégia de prevenção e promoção da saúde de uma unidade básica de saúde. Brazilian Journal of Health Review, v. 3, n. 3, p. 5811-5817, 2020.

DIAS, Ernandes Gonçalves et al. Promoção de saúde na perspectiva da prevenção de doenças parasitárias por meio da educação em saúde com escolares do ensino fundamental. Revista de Epidemiologia e Controle de Infecção, v. 8, n. 3, p. 283285, 2018.

ENRIA, G.; STAFFOLANI, C. Contradicciones de los discursos que dificultan la transformación de las prácticas de promoción a la salud. Hacia la promoción de la salud, Calle, v. 15, n. 1, 2010.

FALKENBERG, Mirian Benites et al. Educação em saúde e educação na saúde: conceitos e implicações para a saúde coletiva. Ciência \& Saúde Coletiva, v. 19, p. 847-852, 2014.

FIGUEIREDO, Elisabeth Almeida; ANTUNES, Daniella Cavalcante; DE MIRANDA, Maria Geralda. Políticas públicas de educação em saúde para a prevenção de comorbidades e doenças cardiovasculares. Revista da Seção Judiciária do Rio de Janeiro, [S.I.], v. 23, n. 45, p. 141-160, jul. 2019. ISSN 2177-8337.

GOMES, Ana Cláudia Ferreira et al. Educação em saúde para prevenção do câncer de pênis: relato de experiência. Brazilian Journal of Health Review, v. 2, n. 4, p. 2961-2964, 2019.

RC: 102791

Доступно в:

https://www.nucleodoconhecimento.com.br/здравоохранение/санитарное- 
JANINI, Janaina Pinto; BESSLER, Danielle; VARGAS, Alessandra Barreto de. Educação em saúde e promoção da saúde: impacto na qualidade de vida do idoso. Saúde em Debate, v. 39, p. 480-490, 2015. LOPES, M. S. V.; SARAIVA, K. R. O.;

LIMA, D. C.; GARCIA, M. P. .; LIMA, E. S. de .; BEZERRA, C. C. . Health education as a tool for the prevention of cardiovascular diseases in the Elderly Health Care Program. Research, Society and Development, [S. I.], v. 9, n. 10, p. e079107382, 2020. DOI: 10.33448/rsd-v9i10.7382. Disponível em: https://rsdjournal.org/index.php/rsd/article/view/7382. Acesso em: 28 aug. 2021.

OBJETIVOS DA ONU - ODS. Objetivo 3. Assegurar uma vida saudável e promover o bem-estar para todas e todos, em todas as idades. Disponível em: <https://gtagenda2030.org.br/ods/ods3/>. Acesso em: 25 ago. 2021

PIMONT, Rosa Pavone. A educação em saúde: conceitos, definições e objetivos. Boletín de la Oficina Sanitaria Panamericana (OSP); 82 (1), ene. 1977, 1977.

RICCI, Ana Patrícia et al. Infecções sexualmente transmissíveis na gestação: educação em saúde como estratégia de prevenção na atenção básica. Brazilian Journal of Health Review, v. 2, n. 1, p. 565-570, 2019.

SALCI, Maria Aparecida; MEIRELLES, Betina Hörner Schlindwein; SILVA, Denise Maria Guerreiro Vieira da. Educação em saúde para prevenção das complicações crônicas do diabetes mellitus na atenção primáriaa. Escola Anna Nery, v. 22, 2018.

SCHALL, Virgínia T.; STRUCHINER, Miriam. Educação em saúde: novas perspectivas. 1999.

SOUSA, Marta Caires; GUIMARÃES, Ana Paula Miranda; AMANTES, Amanda. A saúde nos documentos curriculares oficiais para o ensino de ciências: da lei de diretrizes e bases da educação à base nacional comum curricular. Revista Brasileira de Pesquisa em Educação em Ciências, p. 129-153, 2019.

RC: 102791

Доступно в:

https://www.nucleodoconhecimento.com.br/здравоохранение/санитарное- 
SPERANDIO, Naiara; SPERANDIO, Natália Elvira. A educação em saúde enquanto prática transformadora da realidade social. Educação e Saúde: fundamentos e desafios, v. 1, n. 2, p. 7-14, 2018.

XIMENES, L. B. Análise do conceito de promoção da saúde. Texto Contexto Enferm., Florianópolis, v. 19, n. 3, jul./set. 2010, p. 461-468.

\section{ПРИЛОЖЕНИЕ - СПРАВОЧНАЯ СНОСКА}

7. Люди, которые были частью доктрины гигиенизма, доктрины, родились в середине девятнадцатого века, когда правители уделяли больше внимания здоровью наряду с моральным духом населения. В то время болезнь считалась социальным явлением, затрагивая все аспекты жизни человека, именно через этот контекст возникает очистка воды, сточных вод, уличного освещения, с целью контроля или ликвидации пандемий (ABREU JUNIOR; ДУБ, 2012).

Представлено: Сентябрь 2021 года.

Утвержден: Ноябрь 2021 года.

RC: 102791 Доступно в: https://www.nucleodoconhecimento.com.br/здравоохранениe/санитарное- 